\section{Case Reports in Acute Medicine}

Case Rep Acute Med 2020;3:53-55

DOI: 10.1159/000508701
Published online: August 25, 2020

(C) 2020 The Author(s)

Published by S. Karger AG, Basel www.karger.com/cra

This article is licensed under the Creative Commons Attribution-NonCommercial 4.0 International License (CC BY-NC) (http://www.karger.com/Services/OpenAccessLicense). Usage and distribution for commercial purposes requires written permission.

\title{
A Rare Misdirected Subclavian Venous Catheter to the Neck
}

\author{
Miguel Nuno Lourenço Varela ${ }^{a}$ Luís Flores $^{a} \quad$ Rui Patraquim ${ }^{a}$ \\ Daniel Nunez ${ }^{\mathrm{a}}$ Cristina Granja ${ }^{\mathrm{a}} \mathrm{b}, \mathrm{c}$ \\ antensive Care Medicine 1, Hospital de Faro, Centro Hospitalar Universitário do Algarve, \\ Faro, Portugal; ${ }^{b}$ CINTESIS - Center for Health Technology and Services Research, Faculty \\ of Medicine, University of Porto, Porto, Portugal; 'Department of Biomedical Sciences and \\ Medicine, University of Algarve, Faro, Portugal
}

\section{Keywords}

Critical care · Misplaced central venous catheter - Anterior jugular vein · Subclavian vein

\begin{abstract}
Placement of a central venous catheter (CVC) is not without complications, one of those being misplacement of the catheter tip. This event is dependent on the patient's vascular anatomy, hence unexpected misplacements may occur. We describe a case where a right subclavian CVC was inserted uneventfully, but later found to have migrated into a vein coursing through the midline of the neck, for which only three other cases have been reported. The catheter remained functional and was later removed without further complications.
\end{abstract}

(C) 2020 The Author(s)

Published by S. Karger AG, Basel

\section{Introduction}

Central venous catheter (CVC) placement is an essential skill in emergency settings, but it is not without risks. A misplaced CVC refers to a catheter whose tip is not in a central vein, either as a result of incorrect placement or later due to migration of the tip. Patients' individual anatomic characteristics may predispose to misplacement of CVCs [1]. 


\section{Case Reports in Acute Medicine}

\section{Case Presentation}

A 52-year-old male was admitted to our hospital's emergency department after becoming cyanotic and eventually losing consciousness. Bilateral pneumonia was diagnosed and the patient was promptly intubated due to severe respiratory failure.

A triple-lumen 7-French CVC was emergently placed on the right subclavian vein, without ultrasound guidance. During the procedure, the guidewire failed to progress more than $15 \mathrm{~cm}$, but the procedure was continued since the patient had average height, and subsequently catheter insertion found no resistance. However, after catheter insertion, no blood could be aspirated from the distal port, but saline could be injected smoothly. The two remaining ports were functional and noradrenaline and fentanyl infusions were started through those two ports, with clinical response.

A chest computed tomography was performed, which showed the CVC progressing upwards in the midline of the patient's neck (Fig. 1). Upon palpation of the neck, a thin cylindrical device was noted in the midline, anterior and inferior to the thyroid gland. The catheter tip was deemed to be in the inferior thyroid vein or in a single midline anterior jugular vein and was uneventfully removed soon after placement of a contralateral subclavian CVC.

\section{Discussion and Conclusion}

Displacement to the neck via the subclavian vein into another vein other than the internal jugular vein is very rare, with only two reports to date describing tip misplacement in the inferior thyroid vein, both using peripherally inserted central catheters [2, 3]. Schummer et al. [4] also describe a case of upward migration of a CVC, inserted through the left subclavian into an anterior jugular vein.

Venous drainage of the thyroid gland is done through the superior, middle, and inferior thyroid veins. The latter arise from the inferior border of the thyroid and can form two separate trunks, each draining separately into the ipsilateral brachiocephalic trunk [5]. Yet the catheter seems to have progressed far beyond the inferior border of the thyroid. Alternatively, the anterior jugular vein, which can drain into the ipsilateral subclavian vein, may rarely form a single midline trunk and drain on either side, and more likely corresponds to the cannulated vein in this case [4]. Regardless, misplacement of a CVC inserted through the right subclavian vein into either of these veins presents a rare event, given the potential anatomic variations and the steep angle of drainage of each one into the subclavian vein.

Even though the CVC was misplaced into one of these veins, they allowed for sufficient blood collection and vasopressor infusion for an extended period of time. Awareness of CVC misplacement is necessary to prevent any complications and to enable timely replacement.

\section{Statement of Ethics}

No patient data prone to identify the patient are shown, hence no consent form was requested from the patient. 


\section{Case Reports in Acute Medicine}

\section{Conflict of Interest Statement}

The authors have no conflicts of interest to declare.

\section{Funding Sources}

The authors have no funding sources to declare.

\section{Author Contributions}

M.N.L.V. wrote the initial draft; the remaining authors revised and added content to the draft.

\section{References}

1 Gibson F, Bodenham A. Misplaced central venous catheters: applied anatomy and practical management. $\mathrm{Br} J$ Anaesth. 2013 Mar;110(3):333-46.

2 Imakiire Y, Yanaru T, Kumano H, Nakamori E, Yamaura K. Malposition of Peripherally Inserted Central Catheter Into the Right Inferior Thyroid Vein: A Case Report. Am J Case Rep. 2018 Apr;19:491-3.

3 Ng KS, Teh BT, Siew EP, Leong HK. Malposition of a long central venous catheter in the right inferior thyroid vein - a case report. Singapore Med J. 1996 Oct;37(5):556-8.

4 Schummer W, Schummer C, Bredle D, Fröber R. The anterior jugular venous system: variability and clinical impact. Anesth Analg. 2004 Dec;99(6):1625-9.

5 Testut L, Latarjet A. Tratado de Anatomia Humana, Tomo Segundo. 9th ed. Barcelona: Salvat; 1974. p. 420.
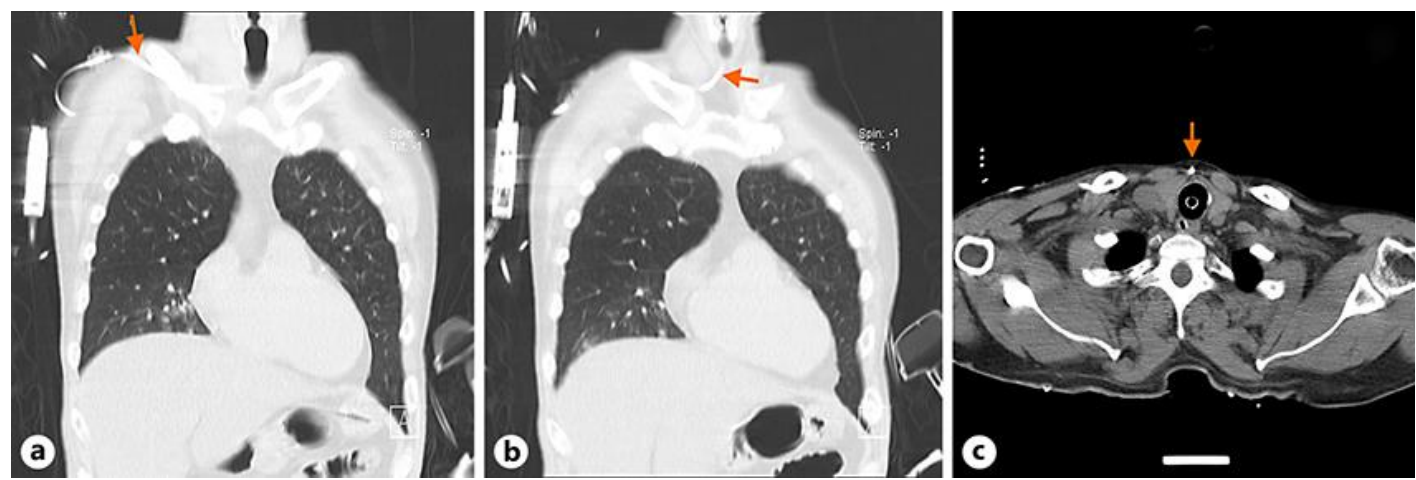

Fig. 1. Chest computed tomography scan showed a subclavian inserted central venous catheter progressing horizontally instead of turning downwards (a) and continuing upwards in the midline (b), anteriorly to the trachea and thyroid gland and ending at the $\mathrm{C} 2$ level (c), as shown by the arrows. 